\title{
ARM BASED HUMAN MACHINE INTERFACE OF PLASTIC EXTRUSION BLOW MOLDING SYSTEM
}

\author{
Archana Ashok More ${ }^{1}$, R. T. Patil ${ }^{2}$ \\ ${ }^{1}$ Student, ${ }^{2}$ Associate Professor, Electronics \&Telecomm dept., R.I.T.Sakhrale, Maharashtra, India, \\ morearchana24@gmail.com,rameshpatil@ritindia.edu
}

\begin{abstract}
This paper designs monitoring and controlling parameters of Plastic Extrusion Blow molding system. This system takes ARM processor as a core and takes CAN bus as communication system by analyzing the human machine interface system. In this Hardware design consist of LPC2138 with ARM7 microprocessor having large memory capacity and CAN communication as Human machine interface control device. In software design Embedded $C$ is transplanted to the ARM core to achieve real time multi task switching. Secondly, GUI is transplanted to display graphics \& text. Write the HMI application program task-unit.
\end{abstract}

Finally LPC 2138 communicates to human machine interface system with CAN bus and HMI of the Plastic Extrusion blow molding system is completed.

Index Terms: Human Machine Interface (HMI), LPC2138, CAN bus (controller Area Network) GUI (Graphical User Interface)

\section{INTRODUCTION}

Now days we are using many Networked embedded systems for monitoring and control the industrial devices. With the scalable networking solution The server enables Web access to

Distributed measurement control systems and provides optimization for educational laboratories, instrumentation, Industrial and home automation. In this paper, we present the principles and to design a system for Plastic Extrusion blow molding system and control by using Advanced RISC Machine i.e. ARM processor and in-build web server application. The main core of the system is an embedded hardware running on a $\mu \mathrm{c}$ OS, a industrial grade RTOS for hard time applications.

Plastics are widely used in industry as one of the basic material comparing with other materials, plastics have many advantages i.e. Lighter weight, easier processing and better mechanical and chemical properties. Molding is one of the most important manufacturing Processes which are capable of mass producing complicated plastics parts with excellent precision.

Now days plastic blow molding machine technology developed rapidly, which makes more and more requirements to human-machine interface of plastic blow molding machine equipped in the field of industrial control. So new style automation equipped with embedded ARM as core to control,
CAN bus as the communication network in order to meet requirements of human machine interface.

\section{INTERACTIVE DATA ACQUISITION SYSTEM}

DATA-ACQUISITION systems are in great demand in industry and consumer applications. In some applications, human beings have been replaced by unmanned devices that will acquire data and relay the data back to the base. There are data-acquisition and control devices that will be a substitute for a supervisor in a multisite job operation. A single person can monitor and even interact with the ongoing work from a machine. An acquisition unit designed to collect data in their simplest form

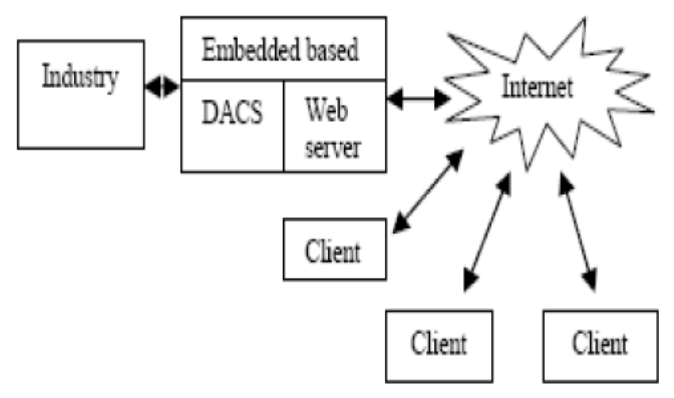

Fig.1 Embedded-web server Architecture 


\section{HUMAN-MACHINE INTERFACE PRINCIPLE}

In this we use new technologies, new devices and computer integrated control technology to design man-machine interface of the plastic molding process but Man-machine interface principle requires mechanical-electrical hydraulic integration equipment. So this ARM based intelligent control system combines the Process features of molding machine. Embedded $\&$ field technologies are utilized on the basis of computer of hardware \& design scheme of software's are discussed.

The closed loop control system composed of ARM controller $\&$ sensors realizes the prompt adjustment of the processing parameters such as temperature, pressure in molding machine. This can meet the requirement of different plastic products. Basically Plastic formation process-manufacture of bottles and hollow-shaped parts. Melting the resin- done in extruder and Form the molten resin into a cylinder or tube (this tube is called parison)The parison is placed inside a mold, and inflated so that the plastic is pushed outward against the cavity wall the part is allowed to cool in the mold and is then ejected $\&$ the part is trimmed. Finally we will control and monitor the parameters of this process with advance embedded technology.

\section{FUNCTIONAL SYSTEM DESIGN}

Self-design high-performance low-cost plastic Extrusion Blow molding machine's electrical control circuit diagram is shown in Figure 1, the control circuit uses LPC2138 as the core device, rotating device is intelligent closed-loop control system of servo motor. It communicates with LPC2138 via serial port. Man-machine interface device connects to LPC 2138 by CAN bus. LPC2138 takes main control tasks as the core device, it accept control commands form humanmachine interface and send parameters of display information, control equipment process sequence, handle keyboard procedure, control temperature and pressure of molding process by actuating electro-hydraulic proportional valve and so on.

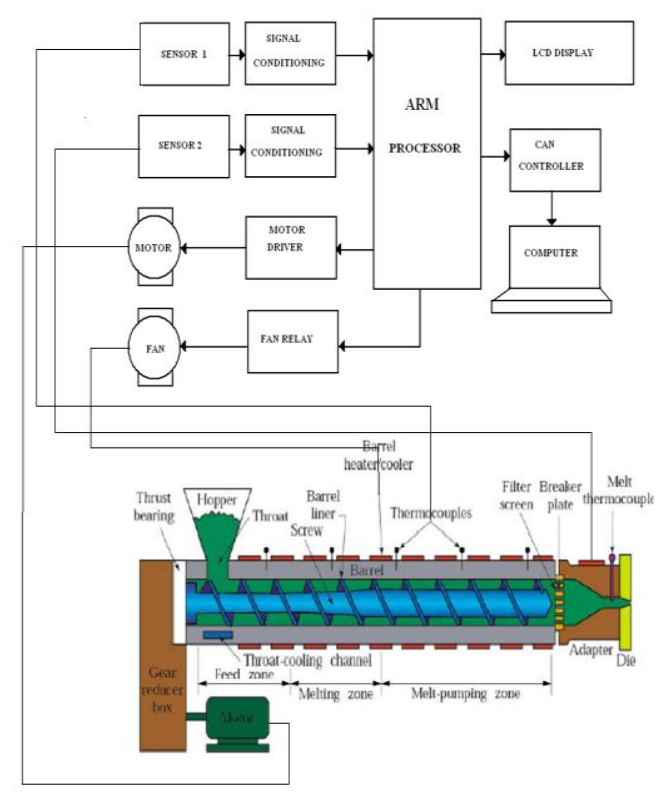

Fig.2 Functional Block Diagram

\subsection{ARM CONTROLLER}

- Leading provider of 32-bit embedded RISC microprocessors, $75 \%$ of market, High performance, Low power consumption, Low system cost.

- ARM is basically a 32-bit RISC processor (32-bit data bus and address bus) with fast interrupt response for use in real time applications.

- ARM is intended for use of applications, which require power efficient processors, such as Telecommunications, Data Communication (protocol converter), Portable Instrument, Portable Computer and Smart Card.

- ARM7TDMI-S processor, running at up to $72 \mathrm{MHz}$.

- Single $3.3 \mathrm{~V}$ power supply (3.0 V to 3.6 )

\section{Power Control in ARM}

Three reduced power modes: idle, sleep, and power-down. ARM cores support basic two reduced power modes- Idle mode and Power-down mode. In Idle mode, execution of instructions is suspended until either a reset or interrupt occurs. Peripheral functions continue operation during Idle mode and may generate interrupts to cause the processor to resume execution. Idle mode eliminates power used by the processor itself, memory systems and related controllers, and internal buses.

In Power-down mode, the oscillator is shut down and the chip receives no internal clocks. The processor state and registers, peripheral registers, and internal SRAM values are preserved throughout Power-down mode and the logic levels of chip output pins remain static. The Power-down mode can be terminated and normal operation resumed by either a reset or 
certain specific interrupts that are able to function without clocks. Since all dynamic operation of the chip is suspended, Power-down mode reduces chip power consumption to nearly zero. Entry to Power-down and Idle modes is coordinated with program execution. For example, in ARM7 power mode control is achieved through the PCON register.

\subsection{TEMPERATURE SENSOR (LM35):}

As per the required power for the molding process we can select the Precision Centigrade temperature sensor LM 35. The LM35 series are precision integrated-circuit temperature sensors, whose output voltage is linearly proportional to the Celsius (Centigrade) temperature.

\section{Features}

- Calibrated directly in ${ }^{\circ}$ Celsius (Centigrade)

- Linear $+10.0 \mathrm{mV} /{ }^{\circ} \mathrm{C}$ scale factor

- Rated for full $-55^{\circ}$ to $+150^{\circ} \mathrm{C}$ range

- Operates from 4 to 30 volts

- Less than $60 \mu \mathrm{A}$ current drain

-Low impedance output, $0.1 \mathrm{~W}$ for $1 \mathrm{~mA}$ Load.

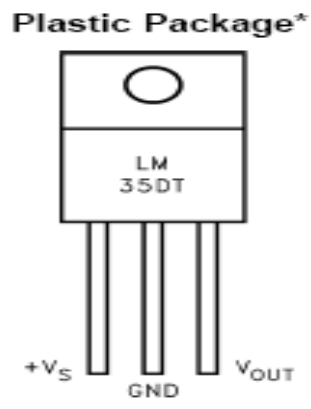

Linear characteristics:

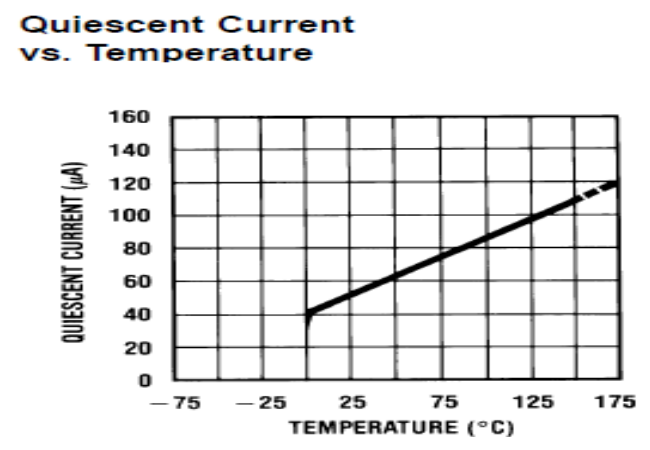

\subsection{PRESSURE SENSOR (MPX2053D)}

As per the required power for the molding process we can select the $50 \mathrm{kPa}$ On-Chip Temperature Compensated and Calibrated Silicon Pressure Sensors. that provide a highly accurate and linear voltage output directly proportional to the Applied pressure.

\section{Features}

- Temperature Compensated Over $0^{\circ} \mathrm{C}$ to $+85^{\circ} \mathrm{C}$.

- Easy-to-Use Chip Carrier Package Options

- Ratio metric to Supply Voltage

- Gauge Ported and Non Ported Options

- Available in Easy-to-Use Tape \& Reel

- Differential and Gauge Pressure Options

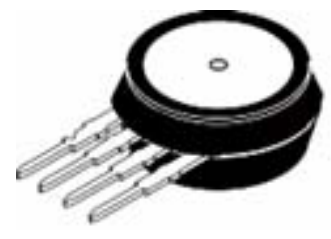

MPX2053D.

\section{SOFTWARE DESIGN FOR BLOW MOLDING MACHINE SYSTEM}

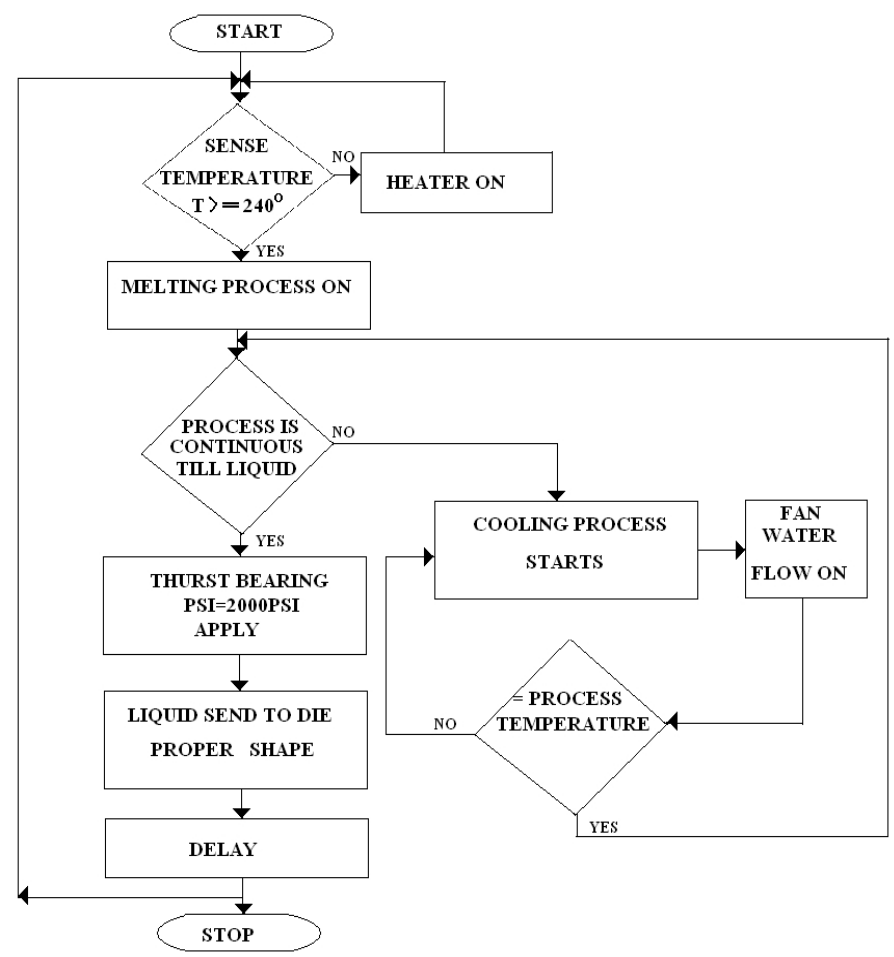

\section{RESULTS AND DISSCUSSIONS}

Following Figure shows execution results of ARM embedded on GUI output Window \& current status of molding machine.

Main control module and user interface module constitute two circuit boards. Man-machine interface module connect main control module, Human-computer interface control unit connects by CAN bus, connects computer by USB Interface or serial communication ports. 


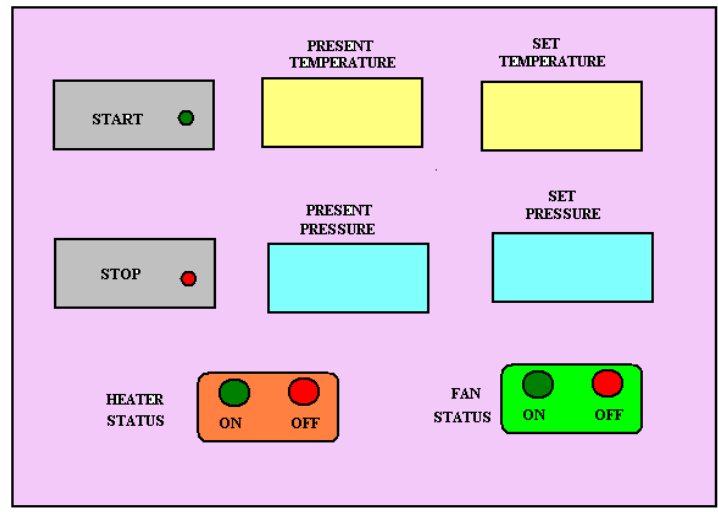

Fig. 4 Human -Machine Interface.

\section{FUTURE SCOPE}

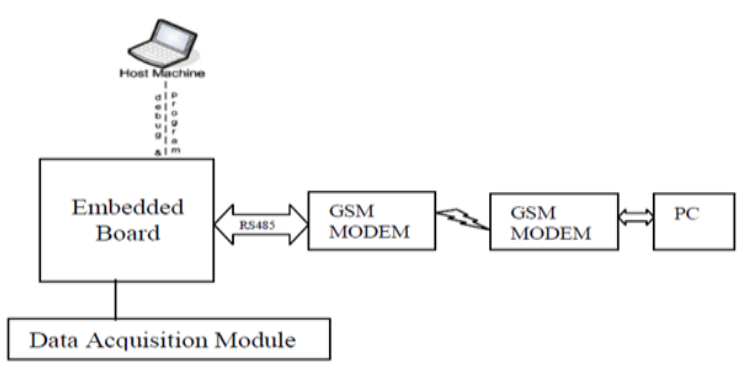

Fig. 5 Block diagram of embedded system with sample devices attached for future work.

The general hardware structure of the remote $\mathrm{I} / \mathrm{O}$ data acquisition and control system based on ARM processor is shown in Fig. 5 The remote I/O data acquisition and control system based on embedded ARM platform has high universality, each acquisition and control device equipped with 24-way acquisition/control channels and isolated from each other. Each I/O channel can select a variety of electrical and non electrical signals like current, voltage, resistance etc., Digital acquisition are done by special ADC. The measured data are stored in external memory in which the memory is act as a data base during web server mode. The ARM processor directly supports the Ethernet service and RS485 communication. Hence the data has been stored and controlled by some other PCs or network via RS485 and Ethernet.

\section{CONCLUSIONS}

It uses high performance processor LPC 2138 as the control core in this paper, it configures large capacity memory, CAN bus controller for large distance. This design allows a Blow molding machine have a human machine interface device, to communicate with the host computer directly, send historical data to the computer and vice versa. The software structure uses embedded C then Transplant GUI in VB to LPC2138. Programming platforms with liquid crystal module is built.
The design of plastic blow molding machine Human Computer interaction system can be transplant easily, develop conveniently. It has multiple functional, good performances, and is very reliable, low power consumption as compare to Analog controlling techniques. So this design is necessary and has practical significance.

\section{ACKNOWLEDGEMENTS}

This research project would not have been possible without the support of my mentor, guide, teachers and friends. I am thankful to all the individuals who encouraged and helped me directly and indirectly to carry this work. Their continuous invaluable knowledgably guidance throughout the course of this study helped me to complete the work up to this stage and hope will continue in further research.

\section{REFERENCES}

[1]. He Yang, Li Kejian, Cai Qizhong, 'Design of ARM Based human machine interface of plastic injection molding machine', Guangxi University of Technology Liuzhou China,2010,pp449-453.

[2]. Zhilei Cui, Jine Wang, "Distributed Intelligent Control System of the Injection Molding Machine Based On ARM controller", Suzhou Vocational University Suzhou, China, 2011, pp 339-342

[3]. Peng Yang, Le Yang, Xin Guo, 'Research ON Embedded Data Display unit based on CAN Bus', Hebei University of Technology Tianjin China,2009,pp 3498-3501.

[4]. Zhi'an Wang Xuhui Wang,Shuangyou Wang, 'A multichannel Temperature acquisition system based on Arm and CAN bus', Handan college Handan, Hebei Province,China,2010,pp32-34.

[5]. Wu-Chung Su, Ching-chih Tsai, 'Discrete -Time VSS temperature Control for a Plastic Extrusion Process with Cooling Systems', Dept of Electrical Engg, National ChungHsing university, Taichung, Taiwan, 2001,pp 619-623.

[6]. 'ARM System Developer's Guide' by Andrew Sloss, Chris Wright, Morgan publishers.

\section{BIOGRAPHIES:}

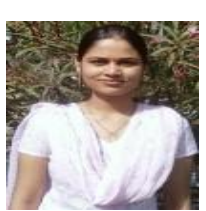

More Archana A. received BE Electronics from Karmaveer Bhaurao Patil College of Engineering Satara and now studying MTech (Electronics) in Rajarambapu Institute of Technology, Sakharale

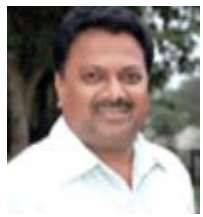

R.T. Patil received the ME in Electronics and currently working as associate professor in Rajarambapu Institute of Technology, Sakharale. His area of specialization is VLSI, Embedded Systems. 